\title{
Contribuição da educação alimentar e nutricional para uma formação omnilateral no Ensino Médio Integrado
}

\section{Contribution of food and nutrition education to omnilateral formation in Integrated High School}

Recebido: 09/04/2020 | Revisado: 28/09/2020 | Aceito: 21/10/2020 | Publicado: 02/02/2021

\section{Brenda Franklin}

ORCID: https://orcid.org/0000-0002-70659981

Instituto Federal de Educação, Ciência e

Tecnologia do Tocantins

E-mail: franklin.brenda07@gmail.com

Jair José Maldaner

ORCID: https://orcid.org/0000-0002-65687910

Instituto Federal de Educação, Ciência e

Tecnologia do Tocantins

E-mail: jair@ifto.edu.br

\section{Rivadávia Porto Cavalcante}

ORCID: https://orcid.org/0000-0002-6568-

7910

Instituto Federal de Educação, Ciência e

Tecnologia do Tocantins

E-mail: riva@ifto.edu.br

\section{Rosa Maria Machado de Sena}

ORCID: https://orcid.org/0000-0002-3616650X

Instituto Federal de Educação, Ciência e

Tecnologia do Tocantins

E-mail: rosa.sena@ifto.edu.br

Como citar: FRANKLIN, B.; MALDANER J. J.; CAVALCANTE, R. P.; SENA, M.M.S.; Contribuição da educação alimentar e nutricional para uma formação omnilateral no Ensino Médio Integrado. Revista Brasileira da Educação Profissional e Tecnológica, [S.I.], v. 1, n. 20, p. e9874, fev. 2021. ISSN 2447-1801.

This work is licensed under a Creative Commons Attribution 4.0 Unported License.

\section{Resumo}

A formação omnilateral é pautada no ideal de ensinar os conteúdos curriculares e desenvolver o ser humano em sua totalidade, com o objetivo de reintegrar o ser humano que está fragmentado pela divisão social do trabalho, tal como o ensino médio integrado profissionalizante propõem. Dentre os temas que uma escola politécnica deve dialogar, tem-se a Educação Alimentar e Nutricional para promoção da alimentação saudável. O objetivo deste trabalho é fazer uma reflexão sobre a Educação Alimentar enquanto conteúdo relevante para a construção de um currículo ampliado, fomentando o senso crítico e a autonomia nos estudantes. Publicações sobre alimentação e nutrição no ensino médio profissionalizante não foram encontradas, fato que alerta para a necessidade de se fazer pesquisas nesse campo.

Palavras-Chave: Educação alimentar e nutricional; Ensino médio integrado; Formação omnilateral.

\begin{abstract}
Omnilateral training is based on the ideal of teaching curriculum content and developing human beings in their entirety. The purpose of this type of training is to reintegrate the human being who is fragmented by the social division of labor, ensuring complete learning, as proposed by integrated vocational secondary education. Among the topics that a polytechnic school should discuss, there is Food and Nutrition Education to promote healthy eating. The objective of this work is to reflect on Food Education as a relevant content for the construction of an extended curriculum, fostering critical sense and autonomy in students. Publications on food and nutrition in vocational secondary education were not found, a fact that warns of the need for research in this field.
\end{abstract}

Keywords: Food and Nutrition Education; Integrated high school; Omnilateral formation. 


\section{INTRODUÇÃO}

Uma formação humana omnilateral, politécnica ou integral significa formar para além dos conteúdos escolásticos, desenvolver o ser humano em todos os aspectos, de acordo com o que afirmava Gramsci (2004) sobre seus ideais de escola unitária. Pressupõe considerar os direitos sociais e humanos previstos no Art. 6ㅇ da Constituição Federal que inclui "[...] a educação, a saúde, a alimentação, o trabalho, a moradia, o transporte, o lazer, a segurança [...]" (BRASIL, 1988). Assim, é um tipo de concepção onde o sujeito é o meio e o fim do processo pedagógico.

Apesar de o ensino médio integrado a um curso profissionalizante ser ofertado com o intuito desse desenvolvimento politécnico do ser humano, o que ocorre muitas vezes é a simples transmissão dos assuntos curriculares. Tratar a educação de modo omnilateral requer tempo, comprometimento, planejamento e recursos que nem sempre estão disponíveis para as escolas e profissionais da educação brasileira. Quando se trata do tema saúde e alimentação, as instituições de ensino deveriam incluí-lo nos diálogos das aulas, seguindo o que é preconizado pela Lei ํㅜ⒒947, de 16 de junho de 2009 que dispõe sobre o atendimento da alimentação escolar. O seu Art. $2^{\circ}$, inciso II aborda que uma das diretrizes da alimentação escolar é

A inclusão da educação alimentar e nutricional no processo de ensino e aprendizagem, que perpassa pelo currículo escolar, abordando o tema alimentação e nutrição e o desenvolvimento de práticas saudáveis de vida, na perspectiva da segurança alimentar e nutricional (BRASIL, 2009, n.p.).

A Educação Alimentar e Nutricional, doravante EAN, é um mecanismo importante para promover hábitos alimentares saudáveis. Ela contribui para a diminuição da prevalência de doenças crônicas, valoriza as culturas juntamente com a soberania alimentar, incentiva a preservação ambiental e a redução do desperdício de alimentos. Ramos (2013) cita que essa temática surgiu no Brasil na década de 1940 e, até os anos 70, resumia-se à inserção de novos alimentos por interesses econômicos, às publicações voltadas para divulgar materiais informativos e à suplementação alimentar para o combate de carências nutricionais.

Nesse sentido, a EAN além de ser um direito dos estudantes, é dever do Estado brasileiro. Lamentavelmente, as políticas educacionais brasileiras se mostram cada vez mais conteudistas, visando apenas a formação das pessoas de acordo com os interesses de governantes e deixando em segundo plano os direitos necessários à vida saudável do cidadão. A escola é um espaço de socialização de bons hábitos alimentares, já o alimento fomenta o corpo humano dando energia para a realização das atividades sociais. Assim, entende-se que a escola se apresenta como um ambiente privilegiado para executar programas de ações de EAN e essa ideia vem sendo considerada na formulação de políticas públicas em alimentação e nutrição. 
Dado o exposto, pretende-se refletir sobre a EAN enquanto conteúdo relevante para a construção de um currículo que integra a formação para a vida, gerando autonomia nas decisões alimentares e autocuidado com a saúde. $\mathrm{O}$ artigo está estruturado em três seções, a primeira trata da questão da educação omnilateral, a segunda aborda a nutrição e seus impactos na formação de nível médio e a terceira traz as considerações finais.

\section{FORMAÇÃO HUMANA INTEGRAL, OMNILATERAL OU POLITÉCNICA}

A forma como a educação é ofertada está estreitamente ligada ao contexto histórico de uma sociedade, principalmente com relação ao mecanismo de fabricação de mercadorias. Ao refletir acerca da educação e do trabalho como princípio educativo, Saviani (2007, p. 154) afirma que "o que o homem é, é-o pelo trabalho". Assim, nenhum homem nasce homem, pois ele ainda aprenderá a ser. Esse aprendizado se dá por meio do trabalho, o qual é também educação. Para Frigotto, Ciavatta e Ramos (2005), o trabalho não é somente uma atividade laborativa ou um emprego, mas está relacionado a toda a dimensão da vida humana. A partir deste entendimento, o trabalho é direito e dever, por isso gera um princípio educativo que não é somente uma didática, mas também tem cunho ético-político. A esses posicionamentos dos autores, correlaciona-se também o conceito de trabalho ontológico, aquele que forma cidadãos, que ensina os aspectos de sobrevivência humana repassados pelas gerações.

O avanço das formas de produção e da divisão de classes ocasionou a bifurcação da educação: um tipo de formação para a classe proprietária dos meios de produção e outro para a classe dos escravos e serviçais. Esta era voltada para o processo de trabalho; aquela, para atividades ditas intelectuais. Essa desagregação da educação com o trabalho, antes indivisíveis, reproduz e fortalece o sistema capitalista. No Brasil, a discriminação do trabalho manual na época da escravidão fomentou esse cenário na educação (FRIGOTTO, CIAVATTA e RAMOS, 2005; SAVIANI, 2007).

Outros autores como Rodrigues (1997), Kuenzer (2005; 2010) mantêm a mesma linha de pensamento, inferindo que o ambiente educacional sofre interferências das relações sociais. Por conta do capitalismo, a escola vem se tornando dualista, separando trabalho intelectual do manual e oferecendo uma formação unilateral para todas as classes. Por outro lado, e contraditoriamente, a formação ampla teve origem no desenvolvimento da indústria, a qual exigiu trabalhadores mais versáteis (MOURA, LIMA FILHO e SILVA, 2015).

Porém, em conformidade com tais estudiosos, a formação humana omnilateral em seu sentido pleno é um projeto de educação nacional marcado por lutas da classe trabalhadora e por inadequações de políticas públicas do Estado brasileiro influenciado pela ideologia da elite capitalista. A respeito disso, Rodrigues (1997, p. 227) já nos chamava atenção para o fato de que a influência desta elite sobre as tomadas de decisões de governantes tornou a educação um terreno de entraves 
ideológicos, dominado pelo empresariado industrial, o qual tem participação direta na deliberação das escolhas "no campo da luta hegemônico-pedagógica, buscando criar os homens à sua imagem e necessidade".

Decorrente disso, os currículos destinados à formação de trabalhadores ainda sofrem as coerções do mercado, visando maior produtividade e lucro para pequena parcela da população. Outrossim, recentes políticas públicas alicerçadas na perspectiva da pedagogia das competências têm fomentado a cisão entre saberes gerais e saberes profissionais distanciando ainda mais a sociedade de uma educação humana integral, tal como disposto na proposta de formação profissional por itinerários formativos da Base Nacional Comum Curricular (BRASIL, 2018). Sobre essa fragmentação histórica dos conhecimentos no processo formativo, Kuenzer (2005) já nos alertava acerca da cisão sobre a política de inclusão excludente do Estado a favor do interesse do capital em detrimento de um ensino amplo que contemple o desenvolvimento geral de trabalhadores.

Do exposto, apesar de que formar adolescentes para alguma profissão fortalece a "unilateralidade em detrimento da omnilateralidade" como afirmou Moura (2013, p. 707), isso não significa que não possam existir cursos profissionalizantes para que se alcance uma educação mais igualitária. Nesta mesma direção, Moura, Lima Filho e Silva (2015) advertem que se deve lutar por escolas técnicas baseadas no princípio educativo do trabalho, onde está o germe da formação humana integral. Portanto, o ensino profissionalizante deve ser uma passagem para se alcançar a educação politécnica (MOURA, LIMA FILHO e SILVA, 2015). No Brasil, onde as lutas ideológicas ora são voltadas para a omnilateralidade, ora para formação instrumental; onde há níveis altos de pobreza e desemprego; e onde muitos jovens precisam trabalhar antes de concluírem os estudos, percebe-se o quanto essa questão é mais complexa e necessita envolver vários setores da sociedade além da educação.

Acerca do ensino médio profissionalizante, a formação técnica no ensino médio, em uma base unitária, é necessária para que se alcance uma nova realidade por meio da politecnia e para superar a dualidade educacional e social. Esse tipo de ensino integral de nível médio tem como objetivo desenvolver os fundamentos das várias ciências (FRIGOTTO, CIAVATTA e RAMOS, 2005). A ideia da formação integrada é reintegrar o ser humano que está fragmentado pela divisão social do trabalho, buscando garantir uma aprendizagem mais completa. A origem deste tipo de formação está na educação socialista, a qual pretendia ser omnilateral nos aspectos físicos, mentais, culturais, políticos e científico-tecnológicos (CIAVATTA, 2005).

Nessa perspectiva, o ensino médio integrado pode ser o embrião da formação humana integral, omnilateral ou politécnica (MOURA, 2013). Dito em outros termos, nesse meio social que não favorece o tipo de educação que se pretende alcançar, resta aos cidadãos comprometidos com a causa aproveitar as contradições sociais e, por meio delas, tentar superá-las. Os aportes de Gramsci (2004) indicam como solução para o impasse da dualidade escolar que, no início da formação, a escola seja única, geral, humanista, colocando o trabalho como princípio educativo. Para o referido autor, a escola é um espaço social onde os alunos devem ser participantes 
ativos. No entanto, para se avançar nessa direção, só é possível, segundo o pensador italiano, "se a escola for ligada à vida" (GRAMSCI, 2004, p. 45).

Os argumentos gramscianos aqui evocados são válidos para a sociedade atual. Principalmente com relação ao estilo de formação e ao tipo de instituição de ensino voltados para formar pessoas críticas, capazes de serem dirigentes. Com base nesse aporte teórico, entende-se que as mudanças na sociedade para alcançar esse patamar de educação não são simples, contudo, consegue-se ir avançando aos poucos com ações centradas na responsabilidade com a transformação social e a resistência às práticas que favoreçam o capitalismo.

Nessa mesma linha de raciocínio, o trabalho de Manacorda (1990) aborda aspectos políticos, de valores, de educação, de humanização e de participação ativa na sociedade. Seus pressupostos estão fundamentados na escola unitária gramsciana, já mencionada. Este estudioso defende uma escola de caráter criativo e ativo, com união de trabalho manual e intelectual, sem finalidades rigorosas para 0 mercado, com integração cultural e com a formação do aluno na totalidade. A contribuição deste autor abre horizontes para que se idealize projetos de formação humana que supere a cisão social histórica provocada pelos movimentos do capitalismo que afeta a educação como formação humana.

Outro ponto importante é que o ensino profissionalizante não deve substituir o ensino básico, ambos se complementam. Ramos (2010) cita os limites organizacionais, financeiros, jurídicos, históricos e ideológicos como impeditivos para a real integração da educação básica com a profissional. Alerta ainda que no ensino médio unitário não há conhecimento somente de cunho geral e específico, ambos formam uma unidade. As singularidades da sociedade não são eliminadas, pois há a síntese da diversidade, tendo o trabalho como base da educação.

O trabalho de Ramos (2010, p. 48) nos apresenta que um projeto de ensino médio integrado à educação profissional precisa levar em conta "sujeitos que têm uma vida, uma história e uma cultura. Que têm necessidades diferenciadas [...] Conhecimentos que são construídos socialmente ao longo da história". Tais contribuições elucidam uma concepção de organização do currículo integrado centrado na noção de sujeito como ser histórico-social que transforma a realidade, formação humana como resultado da formação básica e para o trabalho, o trabalho entendido como princípio educativo, a junção entre conhecimentos gerais e específicos, a profissionalização além da dimensão técnico-operacional e a compreensão histórica dos processos de produção.

A autora Ramos (2010) adverte que a integração curricular vai além de quantificar currículos, carga horária e habilitações profissionais. Deve-se articular em sua organização elementos que auxiliam a concretização do desenvolvimento humano, a saber: os saberes gerais e específicos concernentes ao trabalho, à ciência, à tecnologia, à cultura e ao humanismo os quais são dimensões da vida. 


\section{A CIÊNCIA DA NUTRIÇÃO E SEUS IMPACTOS NA EDUCAÇÃO DE NÍVEL MÉDIO INTEGRADO}

Formar o ser humano em sua totalidade é sem dúvida um desafio. Para isso, é necessário levar em consideração vários aspectos correlacionados com a vida do aprendiz, dentro e fora do ambiente escolar. Concorda-se com a ideia de Freire (1996) de que a leitura do mundo precede a leitura da palavra, ou seja, é preciso considerar os conhecimentos prévios para a construção da aprendizagem. Dá-se importância à leitura de mundo do educando como um ponto de partida, o qual deve ser ultrapassado no desenrolar da aquisição dos saberes.

Moura et al (2007) alertam que a escola na sociedade pós-moderna se adaptou para atender às necessidades econômicas e às novas tecnologias, as quais são passíveis de gerar alienação, sendo o modelo de escola ideal aquele em que há espaço de construção da liberdade, do saber, da cidadania, superando as relações autoritárias em defesa de um tipo de escola que produza e promova a vida em todas suas dimensões. Nesse sentido, para promover a saúde, precisa-se da mobilização dos atores individuais e coletivos, assim como inter-relacionar aspectos de cunho cultural, econômico, social e político, definindo-se dessa forma o caráter multidisciplinar da educação em saúde, na qual é necessário que a pessoa tenha lugar central e seja o fim do processo educativo, transpondo a concepção curricular instrumentalizada e mercadológica (MOURA et al, 2007).

Diante do cenário epidemiológico brasileiro atual, no qual a obesidade ganha destaque, tem-se analisado a EAN nas instituições escolares como ferramenta para formar hábitos alimentares saudáveis a fim de controlar a incidência de doenças de origem alimentar (CHAVES e SOARES, 2011). De acordo com a Organização Mundial da Saúde (OMS), além da obesidade há o aumento de outras doenças crônicas não transmissíveis relacionadas à ingestão inadequada de alimentos pela população, o que caracteriza um quadro de insegurança alimentar em nossa realidade. (OMS, 2003). Assim, dialogar sobre alimentação e nutrição seria uma estratégia para reverter esse panorama através da educação informal e formal, nessa última, a escola é o lugar mais adequado e promissor para tal ideia, já que é onde ocorrem as práticas pedagógicas para a aprendizagem e melhoria da qualidade de vida (RODRIGUES, 2018).

A EAN nas escolas é um direito dos alunos de acordo com o Art. $17^{\circ}$ da Lei no 11.947 de 16 de Junho de 2009 que explicita que tal responsabilidade compete aos Estados, ao Distrito Federal e aos Municípios, destrinchando no inciso III a função de "Promover a educação alimentar e nutricional, sanitária e ambiental nas escolas sob sua responsabilidade administrativa, com o intuito de formar hábitos alimentares saudáveis aos alunos atendidos" (BRASIL, 2009). Logo, as ações que envolvam alimentação e nutrição deveriam por lei ocorrer em todas as escolas de educação básica, a qual inclui o ensino de nível médio, seja o propedêutico ou o profissionalizante.

Uma alimentação saudável leva em consideração a adequação aos aspectos biológicos, socioculturais e ao uso consciente do meio ambiente (BOOG, 2013). A 
EAN é uma estratégia de saúde com o objetivo de melhorar a qualidade de vida através da redução da prevalência de doenças relacionadas à alimentação por meio de ações voltadas à Promoção da Alimentação Adequada e Saudável, a qual é uma das diretrizes da Política Nacional de Alimentação e Nutrição (PNAN) que prevê a inserção da EAN em vários espaços, inclusive nas escolas (BRASIL, 2013).

\begin{abstract}
O desenvolvimento de habilidades pessoais em alimentação e nutrição implica pensar a educação alimentar e nutricional como processo de diálogo entre profissionais de saúde e a população, de fundamental importância para o exercício da autonomia e do auto-cuidado. Isso pressupõe, sobretudo, trabalhar com práticas referenciadas na realidade local, problematizadoras e construtivistas, considerando-se os contrastes e as desigualdades sociais que interferem no direito universal à alimentação. Para isso, constitui-se prioridade a elaboração e pactuação de agenda integrada - intra e intersetorial - de educação alimentar e nutricional para o desenvolvimento de capacidades individuais e coletivas com os diversos setores afetos ao tema (BRASIL, 2013, p. 33).
\end{abstract}

Em estudo recente conduzido na área em pauta, Magalhães e Cavalcante (2019) também conceituam a EAN como uma estratégia para formação do conhecimento, incentivo para a alimentação saudável e controle dos problemas alimentares e nutricionais contemporâneos, destacando que as mudanças no perfil alimentar, no estilo de vida e no padrão de saúde dos escolares diante das ações de EAN são perceptíveis principalmente quando são a longo prazo. Logo, a EAN precisa ser de forma contínua, inserida na realidade dos estudantes e associada aos assuntos escolares para a promoção da saúde e construção de conhecimentos que fazem parte do currículo escolar, levando em consideração o sujeito integralmente (PIASETZKI, 2015).

Instruir os jovens de forma correta para as questões de alimentação saudável é importante também para evitar o surgimento de transtornos alimentares como anorexia e bulimia. Chagas et al (2019) analisaram 120 adolescentes do sexo feminino de uma escola estadual do Rio Grande do Sul e verificaram que $75 \%$ se enquadravam no diagnóstico de eutrofia, porém $83,3 \%$ estavam insatisfeitas com seu corpo. Isso mostra o quanto o público jovem está suscetível a distorções da imagem corporal e a possivelmente aderir dietas sem fundamento científico que podem causar danos à saúde

Por vezes, a promoção da alimentação saudável no ensino médio pode acabar sendo desprezada nos planos pedagógicos por conta dos livros didáticos já conterem informações a respeito. Frente a isso, Teixeira, Sigulem e Correia (2011) avaliaram se os livros de Biologia do ensino médio que são recomendados pelo Ministério da Educação continham conteúdos de nutrição de forma suficiente, ou seja, se os assuntos estavam de forma completa e atualizada. Todos os livros analisados continham informações sobre nutrição, mas, na maior parte, apresentaram-se insuficientes para promover a reeducação alimentar e escolhas alimentares conscientes. Os achados reforçam que se faz necessária a inserção da EAN no currículo escolar, além da revisão periódica dos livros didáticos. 
Acerca dos hábitos alimentares dos adolescentes, um trabalho de pesquisa de Pereira, Pereira e Angelis-Pereira (2017) averiguou quais eram os alimentos mais consumidos em uma escola do município de Lavras/MG e revelou a baixa ingestão de alimentos in natura e elevada de alimentos calóricos, ricos em açúcares simples, sódio e gordura. Pereira, Pereira e Angelis-Pereira (2017) alertam para a urgente necessidade de intervenções educativas para promover a alimentação saudável e para que isso seja efetivo, deve-se ir além de apenas promover conhecimentos nutricionais, sendo necessárias ações integradas, com envolvimento das famílias, escolas, comunidades e do governo.

Correlacionando o conteúdo de nutrição com o que é repassado na matéria de química, Leão, Nery e Freitas (2019) concluíram em seu estudo que, após abordagens lúdicas sobre carboidratos, os alunos participantes do $2^{\circ}$ ano do ensino médio de uma escola pública do Rio de Janeiro tiveram a oportunidade de refletir sobre seus hábitos alimentares e compreenderam que estes devem ser mudados para melhor. De forma semelhante, Piasetzki (2015) trabalhou a EAN com turmas de 2o ano durante um trimestre, envolvendo as matérias de física, química e biologia. Foram retratadas situações do cotidiano dos alunos, buscando assim o maior aproveitamento e compreensão dos assuntos relacionados aos conteúdos escolares, conforme previsto em documentos da política educacional brasileira centrada nos Parâmetros Curriculares Nacionais (PCN) acerca dos temas transversais inseridos em sala de aula.

É interessante fazer essa junção de disciplinas nas atividades de EAN, pois nenhuma ciência isolada é suficiente para o completo entendimento. Trabalhar 0 conteúdo da alimentação transversalmente implica em maiores chances de sucesso na compreensão dos assuntos intra e extracurriculares.

A articulação das várias áreas do conhecimento e das disciplinas da área das ciências, partilhando linguagens, procedimentos e contextos, converge para o trabalho educativo da escola como um todo, ao promover competências gerais dos alunos. [...] Isso requer que os conteúdos formativos das muitas disciplinas tenham uma unidade, em termos de contextos comuns e das competências desenvolvidas [...] (BRASIL, 2000, p. 133).

O estudo de Prado et al (2012) com didáticas lúdicas se mostrou efetivo possivelmente porque não se baseou somente na transmissão de informações. A pesquisa citada ocorreu com escolares do município de Cuiabá/MT e avaliou o efeito de ações de EAN no consumo de alimentos no ambiente escolar. A intervenção causou um efeito positivo principalmente na frequência de consumo de balas, pirulitos e chicletes, diminuindo-a.

Concordando com esses tipos de ações, Ramos, Santos e Reis (2013) indicam que as metodologias para se fazer EAN precisam ser aperfeiçoadas e aprofundadas, considerando que o processo educativo contém subjetividades e é cercado por crenças e valores presentes na alimentação socioculturalmente 
construída. Portanto, é viável considerar a socioantropologia da alimentação e nutrição ligada à outras ciências que fundamentam o ato educativo e que podem possibilitar teorias e metodologias mais eficientes no campo da saúde, alimentação e nutrição.

Os cuidados com a alimentação ganharam destaque na sociedade atual e essas mudanças no perfil das pessoas evidenciam que é preciso aproximar a vida extra escolar com a educação por meio das práticas didático-educacionais. Deve-se ter a cidadania como ensinamento social para os alunos e, para isso, é importante ultrapassar os muros da escola. Isso significa considerar todo o contexto social em que o aluno está inserido, inclusive a alimentação que é um assunto fundamental de se tratar no ambiente escolar porque abrange tanto o aprendizado de matérias teóricas, quanto de saúde. Sem a EAN, o ser humano se torna um alvo fácil para a mídia que muitas vezes propaga insumos de alto valor calórico e baixo valor nutricional, como refrigerantes, sanduíches, sorvetes etc. (LEÃO, NERY e FREITAS, 2019).

É importante também falar da autonomia para se optar de forma consciente entre as alternativas alimentares existentes. Seria a liberdade de escolha frente aos apelos da grande indústria na mídia. As ideias de direito e de autonomia podem estar presentes nas ações de alimentação escolar, possibilitando que o estudante aprenda a ser um sujeito autônomo e que atue diante de sua realidade. $O$ ato de se alimentar na escola deve ocorrer ao mesmo tempo que o educar para a alimentação. Assim, é possível que a EAN componha o currículo escolar e agregue valor aos saberes escolares tradicionais, pois permite instrumentalizar o indivíduo para compreender a sua condição de ser vivo e as dimensões éticas, socioantropológicas e biológicas de sua existência (BARBOSA et al, 2013).

A saúde de forma geral, incluindo os hábitos alimentares, é um tema para ser inserido na escola transversalmente (BRASIL, 2000; BRASIL, 2018). Contudo, falar de alimentação nesse ambiente não é uma tarefa simples e encontra muitas vezes obstáculos, como observou Rodrigues (2018) em sua pesquisa no município Itatuba - Paraíba, destacando que a maioria dos professores só abordavam o assunto quando era conveniente a partir do plano de aula e não de forma transversal. A autora sugere ofertar uma formação continuada dos professores dentro da escola visando meios para ampliar o uso da abordagem do tema transversal de educação alimentar e nutricional em sala de aula.

Tendo em vista os aspectos apresentados, nota-se o quanto é imprescindível falar de EAN no ensino médio. Especificamente no ensino médio integrado, não houve achados de bibliografias que tratassem do tema nas bases de dados MEDLINE, periódicos da CAPES, LILACS, SciELO e Google acadêmico. Todavia, não é desmerecido abordar o assunto em um tipo de ensino técnico profissionalizante. Como foi dito anteriormente, a politecnia é o que deve nortear esse tipo de formação. Então, tratar de saúde, de alimentação e nutrição para os jovens que estudam matérias da educação básica de nível médio juntamente com matérias específicas do curso técnico significa ampliar ainda mais os horizontes dos conhecimentos construídos de modo a reforçar a real significância da educação humana omnilateral. 
Um ensino humano integral fortalece a autonomia dos alunos e ajuda na construção de sua própria identidade.

Silva, Silva e Oliveira (2015) alertam que essa identidade do sujeito sofre interferência também da alimentação, uma vez que o sentido do alimento está além da nutrição para a sobrevivência pois ele carrega um elemento histórico-cultural, já que no ato de comer estão presentes aspectos culturais e religiosos de uma sociedade, os quais a indústria alimentícia instiga mudanças que acabam minimizando a cultura das comunidades. Por conseguinte, os educadores têm a oportunidade de dialogar sobre isso com os alunos, a fim de mostrar que a alimentação não é só ingestão de alimentos e fazer com que o educando reflita e pense criticamente a respeito do contexto social, debate esse que leva os sujeitos a desenvolverem conhecimentos que os capacitam para lutar contra a cultura de massa que o ideário capitalista impõe por meio da indústria alimentícia (SILVA, SILVA e OLIVEIRA, 2015).

\section{CONSIDERAÇÕES FINAIS}

Entende-se que é preciso que, no Brasil, haja a afirmação da escola básica unitária, politécnica e sem dualidade, articulando cultura, conhecimento, tecnologia e trabalho. Para isso acontecer, deve-se superar as relações sociais capitalistas que produzem as desigualdades.

Outro ponto importante é a compreensão do que realmente é a formação integrada, a qual não é apenas a união do ensino médio com um curso profissionalizante, mas um enraizamento mais profundo e entrelaçado de uma instrução geral com uma específica, objetivando sempre proporcionar autonomia, senso crítico e meios para que todos os cidadãos possam ser dirigentes.

Por mais que a EAN venha ganhando destaque nas escolas, ainda é necessário discutir mais sobre as suas possibilidades, seus limites e como ela é realizada. A promoção de uma educação crítica e cultural em torno da alimentação nem sempre ocorre nas escolas. Quando se volta o olhar para o ensino médio profissionalizante, percebe-se que seu ideário é pautado em uma formação humana integral que requer diálogos acerca de temas transversais no meio pedagógico, como saúde e alimentação. Contudo, precisa-se de mais pesquisas e publicações nessa área para compartilhamento de sugestões, êxitos e dificuldades.

É defendida a propagação de informações sobre alimentação e nutrição aos alunos como algo inerente ao currículo escolar. Assim, constrói-se aprendizagens constitutivas do ensino escolar, mas de forma a abordar o ser humano em sua integridade com produção de significados úteis para a vida. O meio escolar deve ser um ambiente que valorize as ações educativas para a promoção da alimentação saudável pois, em conjunto com os conteúdos escolares, o pensamento crítico dos discentes irá se desenvolver considerando o conceito de saúde. 


\section{REFERÊNCIAS}

BARBOSA, N.V.S. Alimentação na escola e autonomia - desafios e possibilidades.

Ciência e Saúde Coletiva, Rio de Janeiro, v. 18, n. 4, p.937-945, abr. 2013.

Disponível em: http://www.scielo.br/scielo.php?script=sci arttext\&pid=S141381232013000400005\&lng=pt\&nrm=iso. Acesso em: 05 jan. 2020.

BOOG, M.C.F. Educação em nutrição: integrando experiências. Campinas: Komedi, 2013.

BRASIL. Constituição da República Federativa do Brasil de 1988. Brasília, DF: Senado Federal. Promulgada em 5 de outubro de 1988. Disponível em: http://www.planalto.gov.br/ccivil_03/constituicao/constituicao.htm. Acesso em: 18 jan. 2020.

BRASIL. Ministério da Educação. Parâmetros curriculares nacionais para o ensino médio: ciências da natureza, matemática e suas tecnologias. Brasília: 2000.

BRASIL. Ministério da Educação. Base nacional comum curricular. Brasília: MEC, 2018. Disponível em:

http://basenacionalcomum.mec.gov.br/images/historico/BNCC_EnsinoMedio_embaix a_site_110518.pdf. Acesso em: 22 de setembro de 2020.

BRASIL. Ministério da Saúde. Política nacional de alimentação e nutrição. Brasília: 2013.

BRASIL. Lei no 11.947, de 16 de junho de 2009. Dispõe sobre o atendimento da alimentação escolar e do Programa Dinheiro Direto na Escola aos alunos da educação básica. Diário Oficial da União, Brasília, DF, 17 jun. 2009. Disponível em: http://www.planalto.gov.br/ccivil_03/_Ato2007-2010/2009/Lei/L11947.htm. Acesso em: 14 jan. 2020.

CHAGAS, L.M. et al. Percepção da imagem corporal e estado nutricional de adolescentes. Revista de Psicologia da IMED, Passo Fundo, v. 11, n. 2, p.69-78. jul./dez. 2019. Disponível em:

http://pepsic.bvsalud.org/scielo.php?script=sci_arttext\&pid=S2175-

50272019000200006. Acesso em: 05 jan. 2020.

CHAVES, T.M.; SOARES, A.P.C.M. Programas de intervenção de educação nutricional no ambiente escolar. Cadernos UniFOA, Volta Redonda, v. 6, n. 1, p. 3140. 2011. Disponível em:

http://revistas.unifoa.edu.br/index.php/cadernos/article/view/1219/1109. Acesso em: 05 jan. 2020.

CIAVATTA, M. A formação integrada: a escola e o trabalho como lugares de memória e de identidade. In: Frigotto, G.; Ciavatta, M.; Ramos, M. (Org.). Ensino médio integrado: concepção e contradições. São Paulo: Cortez, 2005. p. 83-105.

FREIRE, P. Pedagogia da autonomia: saberes necessários à prática educativa. São Paulo: Paz e Terra, 1996.

FRIGOTTO, G.; CIAVATTA, M.; RAMOS, M. (Org.). Ensino médio integrado: concepção e contradições. São Paulo: Cortez, 2005.

GRAMSCI, A. Cadernos do cárcere. 3 ed. Rio de Janeiro: Civilização Brasileira, 2004. 
KUENZER, A. Z. Exclusão includente e inclusão excludente: a nova forma de dualidade estrutural que objetiva as novas relações entre educação e trabalho. In: Saviani D.; Sanfelice, J. L.; Lombardi, J. C. (Org). Capitalismo, trabalho e educação. $3^{\circ}$ ed. Campinas: Autores Associados, 2005. p. 77-96.

LEÃO, I.S.; NERY, I.A.; FREITAS, A.B.R. "Museu do açúcar": uma proposta didática de ensino dos carboidratos para o ensino médio. Scientia Naturalis, Rio Branco, v. 1, n. 2, p. 249-266, 2019. Disponível em:

https://periodicos.ufac.br/index.php/SciNat/article/view/2508. Acesso em: 05 jan. 2020.

MAGALHÃES, Q.V.B.; CAVALCANTE, J.L.P. Educação alimentar e nutricional como intervenção em hábitos alimentares saudáveis no ambiente escolar. Sanare, Sobral, v. 18, n. 01, p.59-67. jan./jun. 2019. Disponível em:

https://sanare.emnuvens.com.br/sanare/article/view/1306/687. Acesso em: 05 jan. 2020.

MANACORDA, M.A. O princípio educativo em Gramsci. Porto Alegre: Artmed, 1990.

MOURA, D.H. Ensino médio integrado: subsunção aos interesses do capital ou travessia para a formação humana integral?. Educação e Pesquisa, São Paulo, v. 39, n.3, p.705-720. set. 2013. Disponível em:

http://www.scielo.br/scielo.php?pid=S1517-

97022013000300010\&script=sci_abstract\&tlng=pt. Acesso em: 06 jan. 2020.

MOURA, D.H.; LIMA FILHO, D.L.; SILVA, M.R. Politecnia e formação integrada: confrontos conceituais, projetos políticos e contradições históricas da educação brasileira. Revista Brasileira de Educação, Rio de Janeiro, v.

20, n. 63, p.1057-1080. dez. 2015. Disponível em:

http://www.scielo.br/scielo.php?pid=S1413-

24782015000401057\&script=sci_abstract\&tIng=pt. Acesso em: 06 jan. 2020.

MOURA, J.B.V.S. et al. Perspectiva da epistemologia histórica e a escola promotora de saúde. História, Ciências, Saúde - Manguinhos, Rio de Janeiro, v.14, n.2, p. 489-501. jun. 2007. Disponível em:

http://www.scielo.br/scielo.php?script=sci_arttext\&pid=S0104-59702007000200006. Acesso em: 03 jan. 2020.

ORGANIZAÇÃO MUNDIAL DA SAÚDE. Diet, nutrition and the prevention of chronic diseases. Geneva, 2003. [WHO- Technical Report Series, 916]. Disponível em: https://apps.who.int/iris/bitstream/handle/10665/42665/WHO TRS 916.pdf;jsessioni $\mathrm{d}=4$ C489046A3D7D1775B92492EF6988C67? sequence $=1$. Acesso em: 22 set. 2020.

PEREIRA, T.S.; PEREIRA, R.C.; ANGELIS-PEREIRA, M.C. Influência de intervenções educativas no conhecimento sobre alimentação e nutrição de adolescentes de uma escola pública. Ciência e Saúde Coletiva, Rio de Janeiro, v. 22, n. 2, p.427-435, fev. 2017. Disponível em:

http://www.scielo.br/scielo.php?pid=S1413-

$81232017000200427 \&$ script=sci_abstract\&tlng=pt. Acesso em: 05 jan. 2020.

PRADO, B.G. et al. Efeito de ações educativas no consumo de alimentos no ambiente escolar. Nutrire: Revista da Sociedade Brasileira de Alimentação e 
Nutrição, São Paulo, v. 37, n. 3, p. 281-292, dez. 2012. Disponível em: https://pesquisa.bvsalud.org/portal/resource/pt/lil-670606. Acesso em: 05 jan. 2020.

PIASETZKI, C.T.R. Educação alimentar e nutricional: uma temática constitutiva do currículo escolar. 2015. 123f. Dissertação (Mestrado em Educação nas Ciências) Universidade Regional do Noroeste do Estado do Rio Grande do Sul, ljuí, 2015. Disponível em: http://bibliodigital.unijui.edu.br:8080/xmlui/handle/123456789/4985. Acesso em: 05 jan. 2020.

RAMOS, F.P.; SANTOS, L.A.S.; REIS, A.B.C. Educação alimentar e nutricional em escolares: uma revisão de literatura. Cadernos de Saúde Pública, Rio de Janeiro, v. 29, n. 11. p. 2147-2161, nov. 2013. Disponível em:

http://www.scielo.br/scielo.php?script=sci_arttext\&pid=S0102-311X2013001100003. Acesso em: 06 jan. 2020.

RAMOS, M. Ensino Médio Integrado: ciência, trabalho e cultura na relação entre educação profissional e educação básica. In: MOLL, J. Educação profissional e tecnológica no Brasil contemporâneo: desafios, tensões e possibilidades. Porto Alegre: Artmed, 2010. p. 42-58.

RODRIGUES, J. O Moderno príncipe industrial: o pensamento pedagógico da Confederação Nacional da Indústria. São Paulo: Cortez, 1997.

RODRIGUES, R.M.S.N. Abordagem da educação alimentar e nutricional no contexto escolar através do Parâmetros Curriculares Nacionais (PCNs) transversal de saúde: um estudo de caso. Revista Científica de Iniciación a la Investigación, Asunción, v. 3, n. 1, p.114-127. 2018. Disponível em:

http://revistacientifica.uaa.edu.py/index.php/rcuaa/article/view/425/340. Acesso em: 05 jan. 2020.

SAVIANI, D. Trabalho e educação: fundamentos ontológicos e históricos. Revista Brasileira de Educação, Rio de Janeiro, v. 12, n. 34, p.152-165. jan./abr. 2007. Disponível em: http://www.scielo.br/scielo.php?script=sci_arttext\&pid=S141324782007000100012. Acesso em: 06 jan. 2020.

SILVA, A.C.B.; SILVA, M.C.C.B.; OLIVEIRA, V.E.R. Educação alimentar e nutricional, cultura e subjetividades: a escola contribuindo para a formação de sujeitos críticos e criativos em torno da cultura alimentar. Demetra: Alimentação, Nutrição e Saúde, Rio de Janeiro, v. 10, n. 2, p.247-257, 2015. Disponível em: https://www.e-publicacoes.uerj.br/index.php/demetra/article/view/14838. Acesso em: 05 jan. 2020.

TEIXEIRA, T.C.; SIGULEM, D.M.; CORREIA, I.C. Avaliação dos conteúdos relacionados à nutrição contidos nos livros didáticos de biologia do ensino médio.

Revista Paulista de Pediatria, São Paulo, v. 29, n. 4, p.560-566, dez. 2011. Disponível em: http://www.scielo.br/scielo.php?pid=S010305822011000400014\&script=sci_abstract\&tIng=pt. Acesso em: 05 jan. 2020. 